\title{
EL ENCOFRADO DESLIZANTE EN LA CONSTRUCCION DE CHIMENEAS INDUSTRIALES
}

\author{
(SLIPFORMING IN THE BIG INDUSTRIAL CHIMNEYS)
}

Nicolás Barrio García, Ingeniero Industrial

Director de KARMAN, Técnicas Especiales, S. A.

\section{RESUMEN}

Este articulo describe el funcionamiento del encofrado deslizante tanto para obra cilíndrica como para ejecuciones troncocónicas. En especial se comenta su aplicación a la construcción de Chimeneas Industriales.

\section{SUMMARY}

This works describes the application of the slipforming system for the construction of cylindric and conical civil works in special for the big staks of chimneys.

\section{El encofrado deslizante en la construcción de chimeneas industriales}

Cuando se habla de los tiempos de ejecución de modernas chimeneas industriales, siempre se mencionan plazos de ejecución muy estrictos:

- Una chimenea de $100 \mathrm{~m}$ se levantó en 23 días de trabajo.

- Otra chimenea de $343 \mathrm{~m}$ de altura se realizó en 76 días.

- El récord de altura en chimeneas, de $381 \mathrm{~m}$, se deslizó en 82 días solamente.

¿Cuál es el método constructivo que permite tal rapidez de realización? ¿Con qué sistema es posible conseguir sobreelevar la construcción una media de $4 \mathrm{~m}$ al día, o incluso más? La respuesta es que la parte exterior de las modernas chimeneas industriales, ejecutada en hormigón armado, se realizan con el empleo del sistema de encofrado deslizante.

En principio el sistema no es tan moderno, nació a principios de siglo para la construcción de silos en EE.UU, hacia 1903. En Europa también se empezó por la ejecución de silos, en 1924, y en seguida se extendió a otros tipos de obras, como depósitos elevados de agua, faros o pilas de puente. En España los primeros ensayos autóctonos se realizan a finales de los años cuarenta y su primera aplicación fue también para la construcción de silos de grano. En la década siguiente se comercializaron sistemas patentados para deslizar cualquier obra en altura de sección recta constante. Las chimeneas se empezaron a construir, en nuestro país, con el sistema de encofrado deslizante, en 1966, y desde entonces el sistema ha permanecido como el método más generalizado, si no exclusivo, para su construcción.
La evolución tecnológica del sistema desde sus orígenes hasta nuestros días ha sido principalmente en el desarrollo de los medios mecánicos empleados, no en su principio fundamental, que todavía permanece invariable.

Este consiste en, con un molde de poca altura, lograr configurar una sección de hormigón vertida en él de forma constante y a la misma velocidad que se eleva dicho molde. La forma de elevar el molde, que al principio era manual y después mecánica, ahora es impulsada por sistemas hidráulicos, consiguiendo un ascenso del molde completamente automático y a velocidad deseada, pero el concepto básico es el mismo. Tratemos de analizarlo con más detalle.

En la figura 1 el encofrado propiamente dicho consta de un molde (1), de altura 1 ó $1,20 \mathrm{~m}$, cuya configuración sigue el perimetro externo e interno de la sección de hormigón a realizar. Ambas partes del molde se solidarizan entre sí por medio de unos pórticos metálicos o yugos (2) que unen rígidamente la parte de molde exterior y la interior.

Además, el yugo permite la fijación de dispositivo de elevación y retenida o gato (3), que tiene capacidad para subir por el tubo de trepada (4), y éste a su vez se apoya en el suelo o cimentación.

El conjunto de yugo, gato hidráulico y tubo de trepada constituye un puesto de elevación de los que se disponen a lo largo del perímetro del molde tantos como sea necesario, a una distancia uno de otro de como máximo 2 metros.

En cada puesto de elevación se fijan tres plataformas diferentes de trabajo: la plataforma intermedia (6), desde donde se vierte el hormigón de forma continua dentro del 

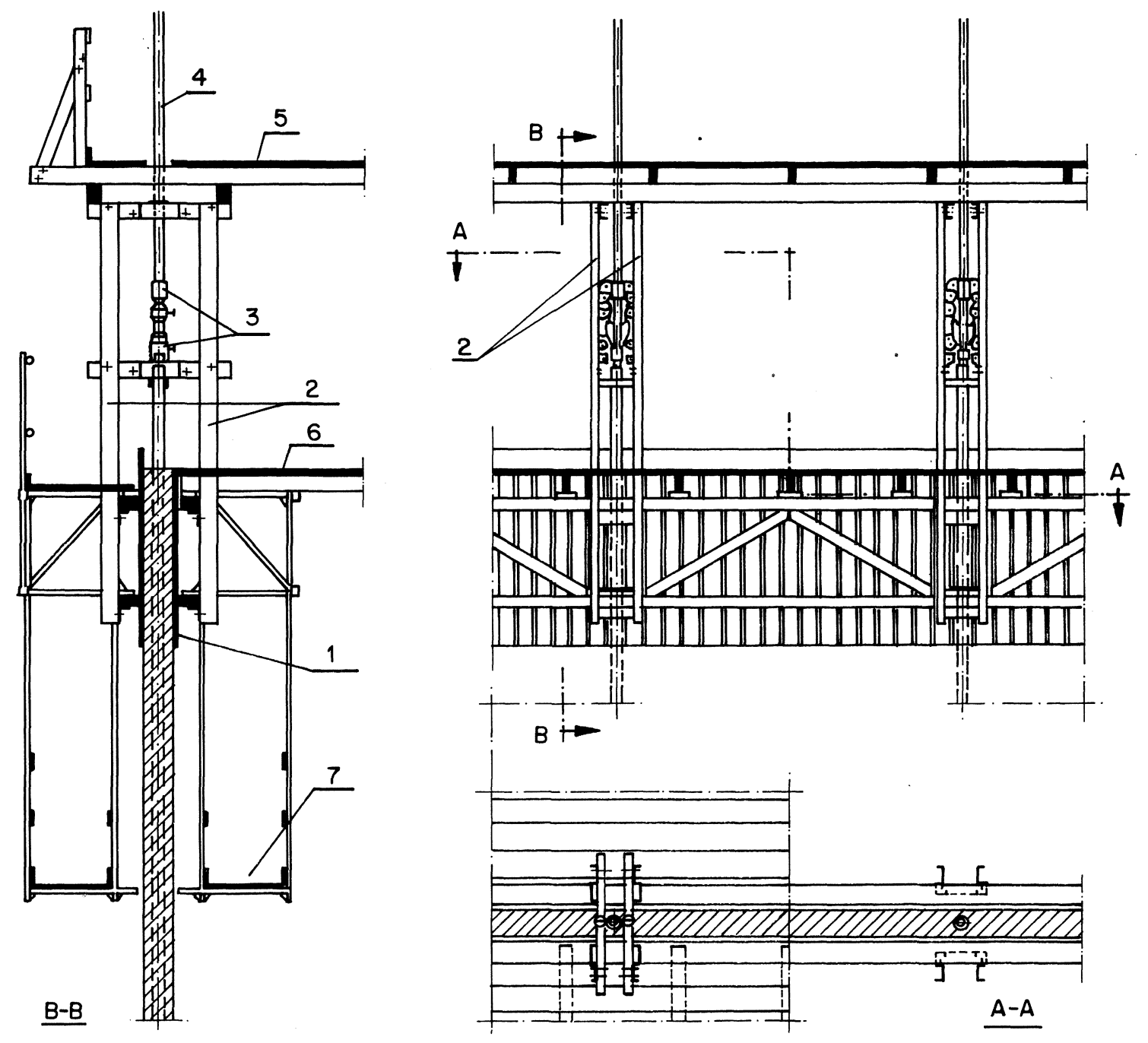

Fig. 1.-Encofrado deslizante para obras rectas.

molde, se colocan las armaduras horizontales y se procede al manejo y mantenimiento de los gatos hidráulicos; la plataforma superior (5) utilizada para el montaje de las armaduras verticales y manejo de los tubos del trepada; y por último la plataforma inferior (7) desde donde se accede, a medida que se eleva el molde a las labores de fratasado y curado del hormigón.

Una vez montado convenientemente todo el sistema, si mediante los dispositivos de elevación y retenida logramos elevar de forma continua los puestos de elevación y con ellos las plataformas y el molde deslizante, llenando de hormigón la parte superior del molde obtendremos por la parte inferior una pared con la configuración deseada. El molde desliza contra el hormigón vertido en su interior, soportándolo y dándole forma en el tiempo en que éste no tiene consistencia propia.

El proceso de fraguado del hormigón determina el tiempo mínimo de permanencia dentro del molde deslizante.
Para un hormigón con un tiempo medio de 5 horas entre el instante de su colocación y el principio de fraguado, con un molde de altura de $1 \mathrm{~m}$, podria conseguirse una velocidad de elevación de $20 \mathrm{~cm} / \mathrm{h}$. Velocidades mayores descubririan el hormigón por la parte inferior del molde sin capacidad para mantener su configuración, mientras que velocidades más lentas producirian una zona del molde llena de hormigón ya fraguado, pudiendo llegar incluso a adherirse uno y otro.

La velocidad de elevación es, pues, función del tiempo de fraguado y por consiguiente de la temperatura. Para temperaturas normales pueden alcanzarse velocidades de elevación de 3,2 a 6 m en 24 horas, siendo normal una velocidad media de 4 horas.

El encofrado deslizante para obras troncocónicas, esto es, encofrados para estructuras donde la disposición en planta entre coronación y base varia de dimensiones en perímetro, espesor de pared, o en ambas cosas a la vez, 
se consigue basándonos en el sistema anterior. Pero rompiendo la rigidez perimetral del molde y disponiendo de una serie de paneles fijos unidos a los yugos, con otra serie de paneles flotantes que por deslizamiento controlado de unos sobre otros nos permite la variación de dimensiones.

En la figura 2 se muestra al conjunto del yugo, que en el transcurso del deslizamiento de una chimenea, por ejemplo, debe acercarse hacia el eje de la misma. Esta reducción se consigue por la acción de los tensores (1) colocados en la parte superior de los yugos y controlados por unas regletas de reducción (2) fijadas a las guías del recorrido de los yugos.

Además, unos tensores tangenciales (3), colocados en la parte inferior del molde, obligan a una disminución perimetral y provocan que los paneles flotantes se cierren sobre los fijos y los cubrejuntas. La reducción de espesor se consigue mediante unos husillos colocados en los yugos y que hacen variar la distancia del molde al yugo (4).

Con este sistema podemos variar de una forma constante el perfil de la estructura consiguiendo una forma troncocónica, o con una ley de reducción variable conseguir perfiles parabólicos u otros cualesquiera.

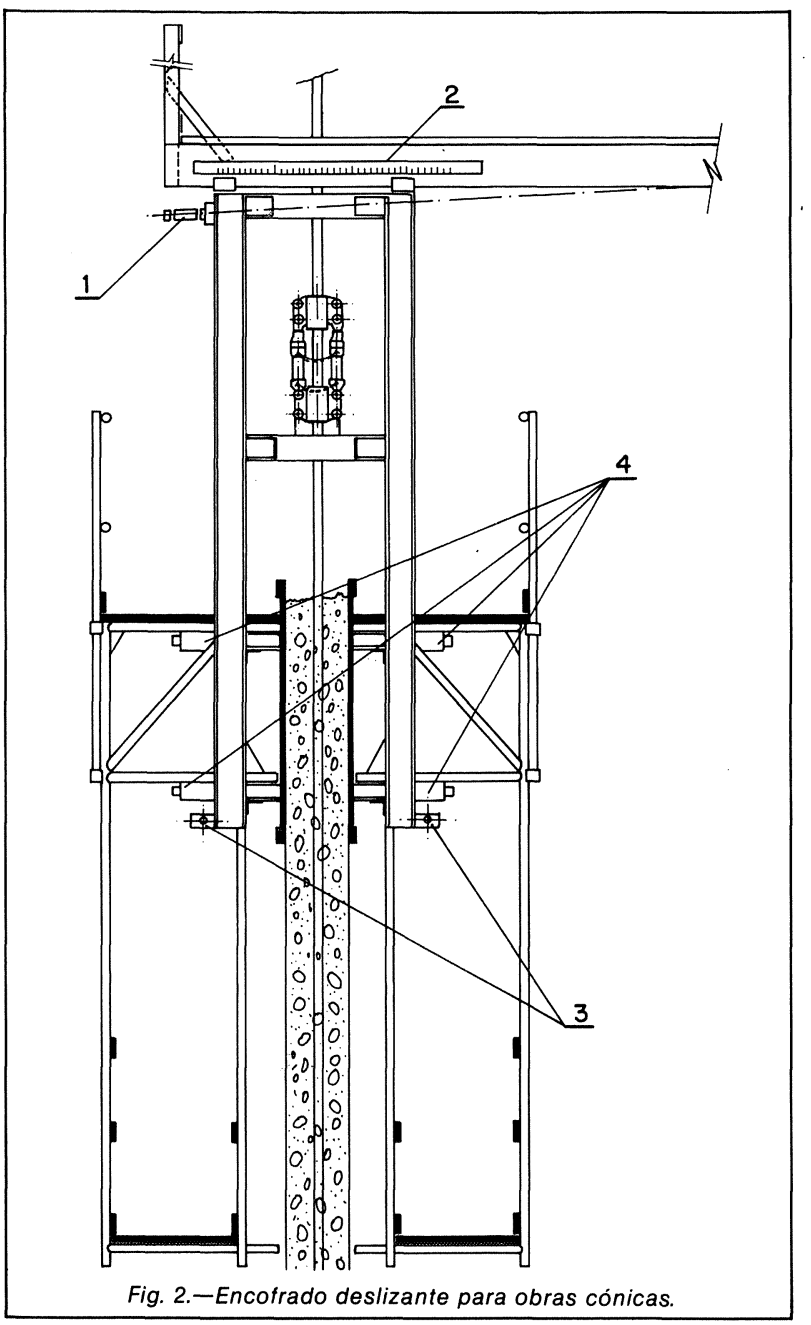

Es importante señalar que en estos sistemas troncocónicos la plataforma superior permanece invariable durante toda la ejecución de la obra. Ello permite controlar perfectamente la verticalidad de la obra siguiendo sus movimientos con plomadas ópticas y regulando la carrera de cada gato hidráulico para realizar las correcciones oportunas.

\section{Ventajas y condiciones de aplicación}

Como consecuencia de la cadena tecnológica, análoga a la que se realiza en la industria, el método de los encofrados deslizantes es una forma de industrialización de la construcción cuyas ventajas y condiciones de aplicación derivan de sus características.

Se citan a continuación, brevemente, las ventajas que pueden resultar de una aplicación racionalizada en este método.

a) Se realizan simultáneamente numerosas operaciones que en otros métodos de construcción se hacen sucesivamente, lo que conduce a una notable reducción del plazo de ejecución (encofrado, ferrallado, hormigonado, colocación de encofrados de huecos, etc.).

b) Pueden suprimirse los tiempos muertos y los estrangulamientos, acoplándose toda función en la cadena tecnológica.

c) Se consigue una gran velocidad de ejecución, alcanzando hasta $6 \mathrm{~m}$ de altura, e incluso más, en un día de trabajo, imposible de alcanzar con el encofrado tradicional.

d) Se alcanza una calidad superior de obra, debido al monolitismo y a la uniformidad en la calidad del hormigón.

e) Se obtiene un gran número de reutilizaciones, ya que existe como posibilidad la fabricación en serie de una gran parte de los elementos del encofrado deslizante de gran duración (yugos, gatos, caballetes para andamios, etc.).

f) Se hace posible la construcción de obras de gran altura, aplicando unos sistemas de elevación adecuados para personal (ascensores) y materiales (cabrestantes, montacargas, etc.).

g) Se obtienen economias sensibles de mano de obra, ya que una gran parte de las labores están mecanizadas, lo que eleva la productividad.

Además las condiciones de aplicación obligan a que el proyecto sea realizado por técnicos competentes, la ejecución de la obra debe ser dirigida por operarios de amplia experiencia, la obra debe disponer de personal especializado en el manejo propio de la maquinaria para la elevación del encofrado, los encofrados deben ser fabricados y montados exactamente, todo ello asegura una amplia fiabilidad en el resultado de la obra.

$$
\text { is is is }
$$

